\title{
Perceptions and Realities: The Role of School Psychologists in Melbourne, Australia
}

\author{
Henry D. Bell and Vicki McKenzie \\ The University of Melbourne, Australia
}

\begin{abstract}
This article investigates the degree to which a consistent understanding of what psychologists do is present in a group of teachers and parents, and compares this with the job functions reported by psychologists themselves. Research on the role of school psychologists has focused on the perceptions of school staff in relation to ideal services, and has given little acknowledgment to the expectations of other clients of school psychologists, such as parents. Common understanding of the range and focus of services available from school psychologists would facilitate effective and appropriate referrals. Services are considered according to models of service delivery from systemic service to an individual case-based model. The current study involved 138 school psychologists, 107 parents, and 100 teachers from government, Catholic, and independent schools across Melbourne, Australia. Participants completed a number of measures, and significant differences between groups were found on 20 of the 30 items relating to school psychologists' responsibilities $(p<.001)$. Associations were also established between student-psychologist ratios and the work practices of school psychologists, specifically the frequency with which assessment $(r=.35, p<.001)$ and counselling $(r=-.25, p<.01)$ tasks were undertaken. It is concluded that service delivery would benefit by enhancing community understanding of the work of school psychologists. Analysis of work practices reflects that demand for assessment services tends to limit the development of systemic and preventative practices in the work of school psychologists.
\end{abstract}

Keywords: school psychology, job functions, service delivery models, community understanding

A number of factors influence the role of school psychologists. While individual practitioners are unable to control factors at the governmental or educational level, some personal and school-based factors, including the perceptions of the educational community, are potential targets for reform. In order to develop a shared understanding of the role, an important first step is to investigate the current perceptions of key stakeholders.

The current study investigates the role of school psychologists as perceived by parents and teachers and compares this with the roles identified by practitioners.

Received January 2013; Accepted April 2013

Address for correspondence: Henry D, Bell, c/- Forest Hill Secondary College 178-180 Mahoneys Road, Burwood East VIC 3151, Australia. Email: bell.d.henry@gmail.com 
In addition, associations between the role and personal and school-based factors are examined. Particular emphasis is placed on relationships between the system of employment and individual and systemic work undertaken by school psychologists, along with associations between student psychologist ratios and job satisfaction.

Service Delivery Models. The services provided by school psychologists are directly associated with the model of service delivery adopted (National Association of School Psychologists, 2010). Adherents of the medical model (the client-centred model) work one on one with a student, with little intervention related to contextual factors (Sheridan \& Gutkin, 2000; Stobie, Gemmell, Moran, \& Randall, 2002). Multiple shortcomings of the client-centred model have been identified (Farrell, 2010; Leadbetter, 2005; Meyers, Meyers, \& Grogg, 2004; Reschly \& Yesseldyke, 2002) and it has been argued that its implementation does not meet the needs of schools (Gutkin \& Conoley, 1990). Support for the use of this model has waivered since the systemic model was introduced into the Australian state of Victoria's government's student support services program (Department of Education, 1998; Thielking, 2006). These two models are easily distinguished based on the respective treatment approaches (Gutkin \& Conoley, 1990).

Users of the systemic model view a student in the context of their school, home, and community. As a result, therapeutic work focuses on both one-on-one sessions, and indirect work such as consultation and the development and implementation of prevention programs (Gutkin \& Conoley, 1990; Thielking, 2006).By engaging with the context, the family and school become involved in treatment (Brown, 1987) and a greater number of individuals can be reached, and hence more effective use is made of the psychologists' skills (Cummings et al., 2004; Farrell, 2010).

A Focus on Systemic Practices. Despite its noted limitations, the client-centred model has remained at the forefront of school psychology at an international level. Idsoe (2003) researched the service delivery models employed by 190 Norwegian school psychologists. Two domains were measured on continua: level (individual to systemic) and function (treatment to prevention). Using a six-point scale (from never to very often), participants indicated the frequency with which they undertook 20 activities across four dimensions (individual treatment, individual prevention, systemic treatment, and systemic prevention). Individual level treatment, including assessment and diagnosis of individuals, were the most frequently undertaken tasks, hence Idsoe concluded that the client-centered model dominated the profession. This result strengthened the notion that school psychologists were willing to maintain the status quo when it came to the model of service delivery (Stobie, 2002).

At a local level, Thielking (2006) found that 81 Victorian school psychologists from government, independent, and Catholic schools undertook a reasonable number of systemic practices. While the total number of these practices was consistent across systems, those with more experience undertook a larger number of systemic practices. The majority (64\%) of school psychologists reported that they often worked from a systemic model and that they also often worked from a client-centred model (63\%). In regards to general practice, $41 \%$ used an equally systemic/client-centred approach, $40 \%$ employed a mainly/predominantly client-centred approach, while only 19\% employed a mainly/predominantly systemic approach. While the seemingly increasing use of systemic practices was seen as promising, they were being incorporated into 
a largely client-centred model of service delivery. It is unclear as to whether further progression to a systemic approach has occurred since 2006.

Although many school psychologists wish to expand their role from traditional client-centred tasks such as assessment, counselling and case management, (BradleyJohnson \& Dean, 2000), to spend more time performing systemic tasks such as consultation (Levinson, 1990) and parent education (Gilman \& Gabriel, 2004), there appears to be a tendency to continue using the client-centred model of service delivery (Idsoe, 2003; Stobie, 2002). This is despite frequent requests from school psychologists for service delivery reforms (Young \& Cavanagh, 2009), industry recognition of the benefits of systemic practices (Hart, 2007), and findings which indicate that the implementation of the systemic model would support the goals of the profession (Idsoe, 2003; Thielking, 2006). Although the field is dedicated to change, a significant transition has not yet occurred (Gilman \& Gabriel, 2004; Sheriden \& Gutkin, 2000). Idsoe (2003) suggested that practitioners were reluctant to employ systemic practices due to feeling uncomfortable using them, which may be explained by lack of training in their use (Thielking, 2006). While training may be relevant, research suggests its influence is inconsistent (Curtis, Hunley, \& Grier, 2002) and that years of experience may also be a factor (Thielking, 2006). Other factors associated with training and experience such as annual hours of professional development may therefore also be impacting on this situation.

Ideal Role. School psychologists are noted for responding and adapting to the needs of clients (Bradley-Johnson \& Dean, 2000; Bramlett, Murphy, Johnson, Wallingsford, \& Hall, 2002; Thielking \& Jimerson, 2006). However, a number of factors influence the role the school psychologist adopts, including governmental, educational, and personal/school issues (Farrell, 2010; Thielking, 2006). Some personal and schoolbased factors, including the perceptions of the educational community are potential areas of influence that may be subject to adaptation.

Previous investigations of the perceptions of the educational community have tended to focus on the ideal role of school psychologists. Thielking and Jimerson (2006) investigated what the role and responsibilities of school psychologists should be according to school psychologists, teachers, and principals in Victoria, Australia. Participants from government, Catholic, and independent school systems were asked to complete the 'School Psychologists' Responsibilities Measure' (Thielking, 2006), using a Likert-style agreement scale, which provided information as to what each group felt should be done by school psychologists. Responses from the 81 school psychologists, 21 principals, and 86 teachers indicated discrepancies between groups in relation to role boundaries, dual relationships, confidentiality, and informed consent. However, similarly to previous studies, the perspectives of parents were not obtained.

While data about desired services has provided useful information, to ensure there is a common understanding and greater efficiency, current perceptions of the actual role also need to be gained. From the limited research conducted, it is clear that within the educational community, there is widespread confusion regarding the role, which has impacted not only on the development of the field but the use of services (Young \& Cavanagh, 2009). As there appears to be little information available to schools, parents, and teachers regarding what services school psychologists provide (Young \& Cavanagh, 2009), the role continues to be unclear (Agresta, 2004) and misunderstood by many (Fletcher et al., 2010). 
Current Role. The first step in developing a shared understanding of the role is to investigate what school psychologists currently do (Kahl \& Fine, 1978; Meyers, Roach, \& Meyers, 2009). School psychologists now undertake a range of activities including: conducting various assessments, consulting on a range of issues, working with parents, in-service training, counselling, program evaluations, research, and responding to critical incidents (Armstrong et al., 2000; Perfect \& Morris, 2011). The problem for many school psychologists is that a large proportion of time is allocated to conducting assessments at the expense of other tasks (Bramlett et al., 2002). The reasons for differences in the time allocated to certain tasks have been researched to a lesser extent.

Curtis et al. (2002) investigated relationships between the proportion of time that 1,411 American school psychologists spent completing different tasks and various demographic characteristics. The authors found that those with higher levels of training and/or more experience conducted more consultations and delivered more in-service training. Researchers have found higher student-psychologist ratios to be associated with more assessments (Farrell, 2010), while Curtis et al. found it to be associated with more assessments and fewer counselling sessions. The small to medium correlations found were seen to indicate that each factor was contributing to task engagement (Curtis et al., 2002).

Thielking, Moore, and Jimerson (2006) overcame inherent difficulties in estimating the time spent in various activities by developing the 'Role of School Psychologists' measure. Victorian-based school psychologists reported how frequently they completed four general tasks (assessment, counselling, program development and delivery, and consultation) using a 4-point scale (never to often). With a response rate of $64 \%$ (33 government, 11 independent, and 37 Catholic-based psychologists), the authors found consistency in the frequency with which activities were undertaken. Despite this, psychologists working in the government system reported higher rates of assessment than those in the Catholic and independent systems. The failure to find further significant differences may have been due to relatively small participant numbers. Irrespective of this, the use of multiple measures to assess the work of school psychologists has produced inconsistent findings, hence the relationships between a number of personal/school-based factors and the tasks undertaken by school psychologists require clarification.

Importance of Task Diversity. Adoption of the systemic model increases the diversity of the tasks undertaken by school psychologists. Task diversity has previously been associated with job satisfaction (Levinson, 1989). Defined simply as a measure of how much people like their job (Spector, 1997), job satisfaction of school psychologists has been attributed to a number of factors such as student-psychologist ratio (Curtis et al., 2002), school system (Thielking et al., 2006), and age (Anderson, Hohenshil, \& Brown, 1984). Other studies have been unable to replicate these results (e.g., Worrell, 2004).

The 81 school psychologists who participated in Thielking et al.'s (2006) study indicated their level of job satisfaction on 18 items, including variety of activities. Based on the findings of Levinson (1990), one may have anticipated that those who undertook various activities less frequently would be less satisfied with their job. Despite those in the Catholic system reporting generally lower, although not significantly lower, involvement in assessment, counselling, programs, and consultation, it was 
government-based school psychologists who reported significantly lower satisfaction with a number of aspects of their role including overall satisfaction.It may therefore be that it is the frequency with which particular activities are undertaken that influences job satisfaction.

Hypotheses. Since Thielking's (2006) study there has been further endorsement for the use of the systemic model from the Australian Psychological Society (APS, 2009) and the literature (see Annan \& Priestley, 2011). In addition, professional development requirements have been tightened (APS, 2009, 2011; Psychology Board of Australia, 2012). Based on these changes it is an opportune time, in addition to investigating the perspectives of parents and teachers, to measure a range of personal and workbased factors, the frequency with which different tasks are undertaken, the number of systemic practices engaged in, the model of service delivery employed, levels of job satisfaction, and the relationships between these factors. In doing so, the following hypotheses will be tested:

1. As a group, compared to teachers, parent responses to the School Psychologist Responsibilities Measure will demonstrate significantly less agreement with school psychologists regarding their professional responsibilities.

2. In keeping with indications from Thielking (2006), school psychologists working in the Catholic sector will report less frequent rates of assessment, counselling, program involvement and consultation, and higher total job satisfaction ratings compared to those in the government and independent systems.

3. Higher levels of experience and training will be associated with a higher frequency of engagement in systemic tasks (consultation and program development/delivery) and a lower frequency of client-centred tasks (assessment and counselling). Relationships with student-psychologist ratios and experience and training will be in the reverse, higher ratios will be associated with less engagement in systemic activities.

4. Frequency of psychologist engagement in systemic practices will be positively associated with higher importance ratings and higher job satisfaction ratings.

\section{Method}

\section{PARTICIPANTS}

One-hundred and thirty-eight school psychologists, 107 parents, and 100 teachers from Catholic, government, and independent schools across Melbourne, Australia participated in the research. All schools involved had access to psychological services via their own psychologist or through the Department of Education and Early Childhood Development (DEECD), Catholic Education Office (CEO), OnPsych or OzChild services.

\section{MATERIALS}

Three surveys described below, all derived from measures designed and used by Thielking and colleagues (2006), were used in the study.

School Psychologist Survey. The modified School Psychologist Survey contained six sections: demographics, school psychologists' role, responsibilities of the school 
psychologist, model of service delivery, importance of model of service delivery, and job satisfaction.

Demographics. This contained items relating to gender, age, registration, professional development, experience, employment status, and school demographics (system, year levels, and location).

Role of School Psychologists' Measure. Psychologists indicated the frequency with which they completed 19 tasks under four role headings: assessment, counselling, program development and delivery, and consultation on a 4-point scale (never, rarely, sometimes, often). Scores were compiled under the appropriate sub-scale to produce four activity ratings. Thielking reports that Cronbach's alpha for the four scales has ranged from 0.69 to 0.91 (Thielking, 2006).

School Psychologist Responsibilities Measure. This measure was originally designed to assess the ideal responsibilities of school psychologists (Thielking \& Jimerson, 2006). To assess current work practices, the items remained the same, however the phrasing of the question was modified to gauge the frequency of task engagement. The same 4-point scale was used as in the previous measure.

Model of Service Delivery Scale. The 'Model of Service Delivery Scale' (MSDS) comprised a list of 21 systemic activities. Respondents were required to indicate which activities they did and did not complete. By totaling the number of 'yes' responses, a score for the practitioners' systemic practices was obtained (0-21) with higher scores indicating greater involvement in systemic practices. This scale has a published Cronbach's alpha of 0.68 (Thielking, 2006). Although an alpha of 0.70 or above is generally required for statistical analysis (Hair, Anderson, Tatham, \& Black, 1998), values lower than 0.70 are expected in research (Field, 2009) and as the value was above 0.60, it was deemed satisfactory (Robinson, Shaver, \& Wrightsman, 1991). School psychologists were also asked to indicate the frequency with which they employed systemic and client-centered models (never, rarely, sometimes, or often), as well as which model they used most of the time (predominantly one, mainly one/partly the other, or both equally).

Importance of Model of Service Delivery Scale. The 'Importance of Model of Service Delivery Scale' (MSDSi) required participants to indicate, on a 4-point scale, the importance they placed on each of the 21 MSDS items (not important - extremely important). Item responses were totaled with higher scores indicating greater importance. The scale has a reported Cronbach's alpha of 0.90 (Thielking, 2006).

Job Satisfaction Scale. This 18-item measure contained a 5-point scale to assess school psychologists' levels of satisfaction with their work (very unsatisfiedvery satisfied). A number of aspects of job satisfaction were assessed including: resources, professional support, development, tasks, time, and career. A total job 
satisfaction score (0-72) was obtained with higher scores on this scale indicating greater job satisfaction. This scale has a Cronbach's alpha of 0.89 (Thielking et al., 2006).

Teacher Survey and Parent Survey. The 'Parent Survey' was derived from the modified 'Teacher Survey'. The components were consistent across surveys with demographic items adjusted as necessary.

Demographics. Teacher demographic items covered gender, system of employment (government, Catholic, independent) and year level (primary, secondary or combined). The frequency of contact with the school psychologist was also assessed. In the Parent Survey, items related to the placement of their child (i.e. system and year) and parent awareness of the availability of a school psychologist.Two items assessed whether or not their child or any other members of their immediate family had visited a school psychologist.

Understanding of School Psychologists' Role Scale. Parents and teachers were asked to indicate their level of agreement (strongly disagree-strongly agree) with five items regarding their knowledge of the role. Items related to the clarity of the role, explanations of the role, awareness of training and qualifications, knowledge of the referral process, and their ability to explain the services available (Thielking, 2006).

School Psychologist Responsibilities Measure. Parents and teachers completed the scale as described above. For each item they were required to 'please indicate the frequency with which you believe school psychologists ....'

MSDS and MSDSi. These two scales measured perceptions of the model employed by school psychologists and the importance placed on each systemic activity.The results from these two scales were not analysed in this study due to a high proportion of missing data.

\section{PROCEDURE}

Upon approval from the relevant ethics boards, school principals across Melbourne were contacted and invited to have their school participate. Participating principals then received the appropriate documents for distribution. In order to recruit additional psychologists, Network Managers and Stream Leaders from the CEO and DEECD, along with individual school psychologists, were contacted. Data was analysed using SPSS version 20.0 software.

\section{Results}

Data Preparation and Screening. Response rates for school psychologists, parents, and teachers were $57.0 \%, 27.8 \%$, and $59.8 \%$ respectively. Initial screening resulted in the identification of a small amount of missing data, which was found to be missing completely at random. Missing data was replaced with group means, as suggested by Tabachnick and Fidell (2007). Uni- and multivariate outliers were removed. 
TABLE 1

Proportion of Sample Recruited From Each School System By Participant Group

\begin{tabular}{lccc}
\hline & Government & Catholic & Independent \\
\hline School psychologist* & 63.2 & 16.2 & 14.7 \\
Parent & 6.8 & 71.6 & 21.6 \\
Teacher & 12.2 & 54.1 & 33.7 \\
\hline
\end{tabular}

*The school psychologist numbers do not add up to $100 \%$ as $5.9 \%$ worked across school settings

Consequently the sample was reduced to 136 school psychologists (116 female), 102 parents ( 88 female), and 98 teachers ( 83 female). Responses from a further eight participants who worked across settings were removed, leaving data from 128 school psychologists for the subsequent analysis. Following the transformation of assessment and counselling frequency variables, all assumptions were met within groups for all variables of interest.

Demographics. As can be seen in Table 1, there was an imbalance in the representation of systems across participant groups. In comparing teacher and parent levels of interaction with school psychologists, teachers reported moderate levels of contact with school psychologists, with $59.2 \%$ reporting daily/weekly contact. In contrast $5.9 \%$ of parents did not know that the service was available at their school and $24.5 \%$ were unsure. School psychologists were aged between 24 and 69 years $(M=40.32, S D=$ $11.51)$, with .01 to 40 years experience $(M=8.27, S D=8.44)$, the majority of whom had completed a master's degree $(58.8 \%)$. Although $24.4 \%$ of APS members $(60.3 \%$ of the sample) belonged to the APS's College of Educational and Developmental Psychologists and 7.4\% to other colleges, $68.3 \%$ did not belong to any college. Psychologists reported undertaking between 0 and 200 hours of professional development in the previous 12 months $(M=43.52, S D=29.39)$. School psychologists tended to work across primary and secondary settings $(79.4 \%)$, with few working exclusively in primary $(10.3 \%)$ or secondary settings $(9.5 \%)$.

Figure 1 indicates that the majority of psychologists reported using both systemic and client-centred approaches. Overall, 7\% reported using predominantly

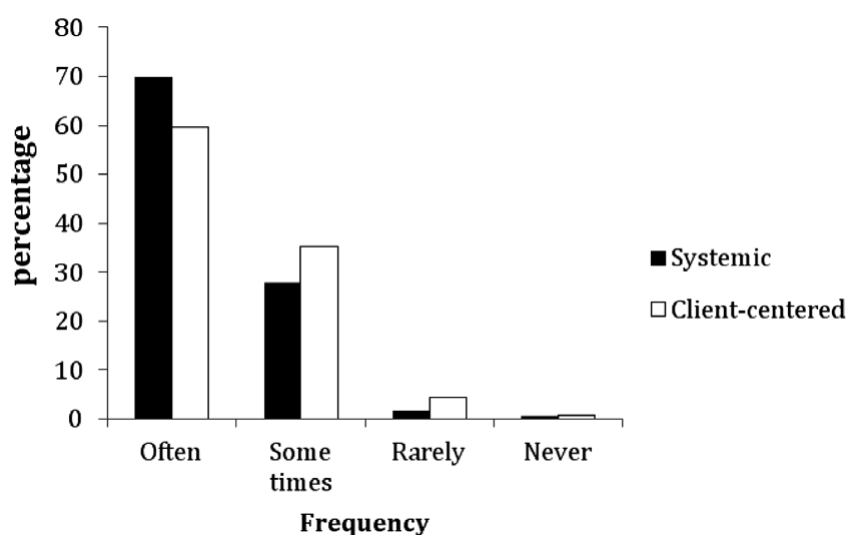

FIGURE 1

Percentage of psychologist responses for systemic and client-centered approaches. 
TABLE 2

Parents' and Teachers' Self-Reported Understanding of the Role of School Psychologists

\begin{tabular}{|c|c|c|c|c|c|c|c|}
\hline \multirow[b]{2}{*}{ Understanding item } & \multicolumn{2}{|c|}{$\begin{array}{c}\text { Parent } \\
(102)\end{array}$} & \multicolumn{2}{|c|}{$\begin{array}{c}\text { Teacher } \\
\text { (98) }\end{array}$} & \multirow[b]{2}{*}{$t(198)$} & \multirow[b]{2}{*}{$p$} & \multirow[b]{2}{*}{$d$} \\
\hline & $M$ & $S D$ & $M$ & $S D$ & & & \\
\hline Confidently tell others about service & 3.67 & 1.21 & 4.26 & 1.08 & -3.64 & $<.001$ & 0.25 \\
\hline Clear and obvious role & 3.48 & 1.02 & 4.32 & .08 & -6.44 & $<.001$ & 0.42 \\
\hline Role has been explained & 2.90 & 1.17 & 4.04 & 1.06 & -7.17 & $<.001$ & 0.45 \\
\hline Aware of training & 3.29 & 1.12 & 4.00 & .96 & -4.80 & $<.001$ & 0.32 \\
\hline Understand referral process & 3.03 & 1.15 & 4.25 & .92 & -8.28 & $<.001$ & 0.51 \\
\hline
\end{tabular}

client-centred, $27.9 \%$ reported using mainly client-centred, $43.4 \%$ equal proportions, $23.5 \%$ mainly systemic, and $4.4 \%$ using predominantly systemic.

Teacher and Parent Understanding. Table 2 presents the means, standard deviations and $t$ test results for parents' and teachers' self-rated understanding of the role.

The Responsibilities Of School Psychologists According to Parents, Teachers, and School Psychologists. Table 3 provides the means and standard deviations from responses to the 30 School Psychologists Responsibilities Measure items obtained from parents, teachers, and school psychologists.

Prior to analysis, responses to the 30 items were correlated and the resulting matrix investigated for multicollinearity. With the exception of items 28 and 29, correlations were found to be well below 0.80 . Subsequently, item 29 was removed from the analysis and a series of one-way between groups univariate analysis of variance (ANOVAs) were conducted on the mean group responses to the remaining items. Due to the large number of DVs and in order to reduce Type 1 errors, the alpha value was set at $\leq .001$.

Table 3 includes the results of the ANOVAs. Post-hoc Tukey HSD comparisons were then conducted to determine which groups differed on the 20 significant results. Among other responsibilities, parents reported that school psychologists provided career guidance to students, provided and charged teachers for counselling at a higher frequency than school psychologists reported $(p \leq .001)$ but not teachers $(p>.05)$ and that they conducted assessments and made IQ reports available to teachers less frequently $(p \leq .001)$. Both parents and teachers believed that school psychologists administered discipline, included counselling as part of disciplinary procedures, made counselling records available to teachers, and informed teachers of students' attitudes towards them more frequently than school psychologists reported $(p \leq .001)$. A followup Pearson's chi-squared analysis indicated that parents demonstrated significantly more disagreements than teachers did with school psychologist ratings, $\chi^{2}(1)=9.00$, $p<.01$.

Work Practices of School Psychologists Across Systems. Figure 2 and Table 4 present the means and standard deviations, for those psychologists working exclusively in one system, on scales relating to work practices and job satisfaction.

A MANOVA was conducted to compare the three psychologist groups on the work practice variables assessed. Multicollinearity between the work practice variables was assessed, with no correlation exceeding .75, Box's M $(p=.121)$ and Levene's statistic 
TABLE 3

School Psychologists' Responsibilities By Group

\begin{tabular}{|c|c|c|c|c|c|c|c|c|c|c|}
\hline \multirow{2}{*}{\multicolumn{2}{|c|}{$\begin{array}{l}\text { As a school psychologist I . . / I } \\
\text { believe the school } \\
\text { psychologist ... }\end{array}$}} & \multicolumn{2}{|c|}{$\begin{array}{l}\text { Psychologist } \\
(N=136)\end{array}$} & \multicolumn{2}{|c|}{$\begin{array}{c}\text { Parent } \\
(N=102)\end{array}$} & \multicolumn{2}{|c|}{$\begin{array}{l}\text { Teacher } \\
(N=98)\end{array}$} & \multirow[b]{2}{*}{$F(2,335)$} & \multirow[b]{2}{*}{$p$} & \multirow[b]{2}{*}{$\eta^{2}$} \\
\hline & & $M$ & $S D$ & $M$ & $\overline{S D}$ & $M$ & $\overline{S D}$ & & & \\
\hline 1. & $\begin{array}{l}\text { Assist teachers in } \\
\text { discipline }\end{array}$ & 2.62 & .95 & 2.39 & .92 & 2.35 & .96 & 2.87 & $>.05$ & .02 \\
\hline 2. & $\begin{array}{l}\text { Administer discipline to } \\
\text { students }\end{array}$ & .32 & .49 & 1.89 & .98 & 1.72 & .79 & 17.74 & $<.001$ & \\
\hline 3. & $\begin{array}{l}\text { Conduct research on school } \\
\text { issues }\end{array}$ & 2.01 & .89 & 2.98 & .81 & 2.95 & .88 & 49.40 & $<.001$ & .23 \\
\hline 4. & $\begin{array}{l}\text { Be up to date on relevant } \\
\text { research }\end{array}$ & .32 & .73 & 3.43 & .68 & 3.58 & .59 & 4.16 & $>.01$ & .0 \\
\hline 5. & Conduct IQ assessments & 45 & .96 & 2.68 & .89 & 3.18 & .96 & 19.82 & $<.001$ & \\
\hline 6. & $\begin{array}{r}\text { Conduct } \\
\text { assess }\end{array}$ & 3.30 & .82 & 2.81 & .98 & 3.24 & .82 & 10.41 & & \\
\hline 7. & $\begin{array}{r}\text { Provid } \\
\text { stuc }\end{array}$ & 3.64 & .64 & 3.64 & .55 & 1 & .27 & 8.17 & $<.001$ & \\
\hline 8. & $\begin{array}{l}\text { Be th } \\
\text { stu }\end{array}$ & 94 & .96 & 3.08 & .75 & 3.14 & .66 & 1. & $>.05$ & \\
\hline 9. & $\begin{array}{r}\text { Provi } \\
\text { stc }\end{array}$ & 1.74 & .71 & 2.27 & .99 & 7 & .81 & 12.09 & & \\
\hline 0 . & Coun & 84 & .74 & 2.36 & 1.02 & 2.20 & .86 & 11.48 & $<.001$ & .0 \\
\hline 1. & Coun & 3 & .87 & 2.82 & .82 & 2.85 & .73 & 29.92 & & \\
\hline 2. & $\begin{array}{r}\text { Orga } \\
\text { stu }\end{array}$ & 47 & .79 & 2.79 & .90 & 3.12 & .76 & 17.72 & & \\
\hline 3. & $\begin{array}{r}\text { Prov } \\
\text { te }\end{array}$ & 2.50 & .79 & 2.93 & .88 & 70 & .87 & 7.19 & $<.001$ & \\
\hline 4. & $\begin{array}{r}\text { Provi } \\
\text { to }\end{array}$ & 3.45 & .69 & 3.19 & .79 & 3.10 & .83 & 6.82 & $>.001$ & \\
\hline 15. & agent within & 3.58 & .61 & 3.35 & .71 & 50 & .5 & 3.72 & 01 & \\
\hline 6. & $\begin{array}{r}\text { Let } r \\
a b\end{array}$ & 90 & .90 & 3.11 & .91 & 3.04 & .95 & 1.55 & $>.05$ & \\
\hline 17. & $\begin{array}{r}\text { Allov } \\
\text { co }\end{array}$ & 1.15 & .41 & 2.39 & 1.18 & 2.31 & .16 & 67.70 & $<.001$ & \\
\hline 8. & hers of student's & 1.61 & .73 & 2.15 & .99 & 2.35 & .94 & 22.95 & $<.001$ & .1 \\
\hline 19. & ports available to & 3.13 & 1.14 & 2.63 & .97 & 2.88 & 1.04 & 0. & $<.001$ & \\
\hline 20. & $\begin{array}{l}\text { Teach subjects as well as } \\
\text { counsel }\end{array}$ & 1.08 & .34 & 1.97 & .94 & 1.39 & .77 & 70 & $<.001$ & \\
\hline 1. & $\begin{array}{l}\text { Charge a fee to teachers for } \\
\text { counselling }\end{array}$ & 1.01 & .08 & 1.85 & 1.00 & 1.10 & .35 & 68.15 & $<.001$ & \\
\hline 2. & $\begin{array}{l}\text { Inform teachers of students } \\
\text { receiving counselling }\end{array}$ & 6 & 06 & 2.41 & 1.02 & 87 & 1.08 & 4.50 & - & \\
\hline 3. & $\begin{array}{l}\text { Inform } \\
\text { par }\end{array}$ & 3.73 & .77 & 3.16 & 1.05 & 3.27 & .92 & 13.36 & $<.001$ & \\
\hline 24. & $\begin{array}{l}\text { Inform secondary student's } \\
\text { parents of counselling }\end{array}$ & 0 & .94 & 2.84 & .99 & 2.87 & .96 & 5.10 & $>.001$ & \\
\hline 25. & $\begin{array}{l}\text { Mandate counselling for } \\
\text { some students }\end{array}$ & 2.40 & .89 & 2.54 & .86 & 2.59 & .85 & 1.54 & $>.05$ & \\
\hline 26. & $\begin{array}{l}\text { Include counselling in } \\
\text { disciplinary procedures }\end{array}$ & 72 & .82 & 2.42 & .92 & 2.22 & .86 & 21.40 & $<.001$ & \\
\hline
\end{tabular}


TABLE 3

Continued

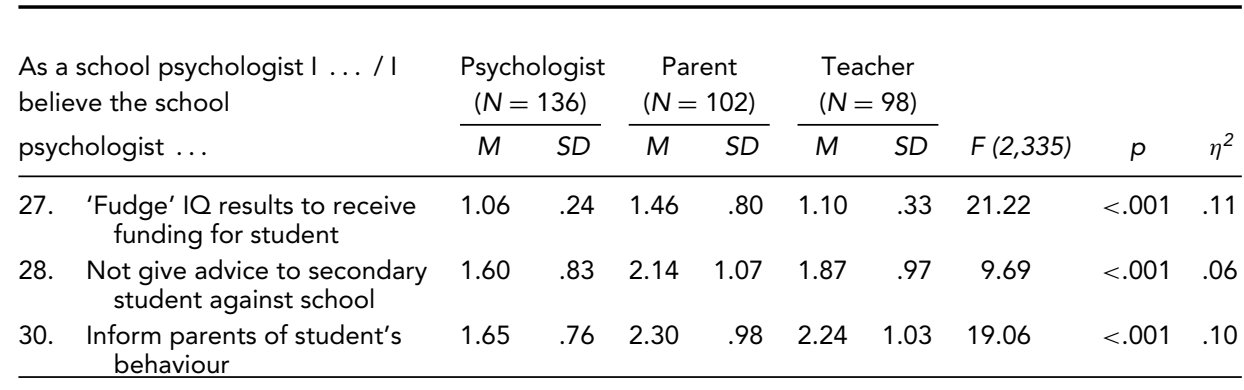

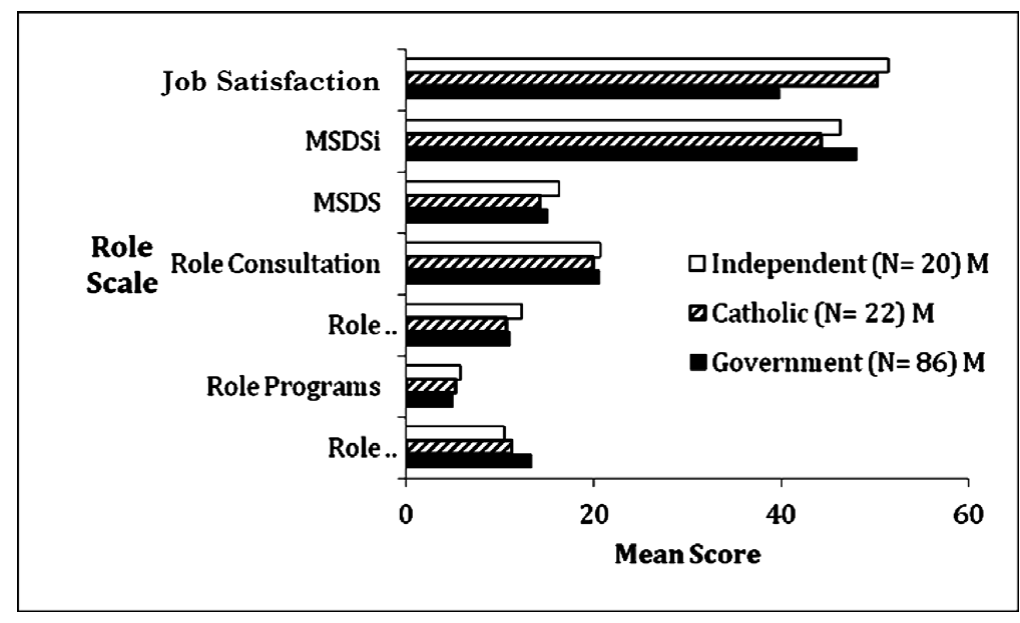

\section{FIGURE 2}

Mean psychologist role scores by system.

$(p>.05)$ did not reach statistical significance. The use of a MANOVA was therefore supported. The Pillai's Trace statistic indicated that a significant difference occurred, $F(14,240)=4.14, p<.001, \eta^{2}=.19$. Results show significant differences on frequency of assessment, $F(2,125)=15.18, p<.001, \eta^{2}=.19$, and total job satisfaction scales, $F(2,125)=14.42, p<.001, \eta^{2}=.19$. The remaining work practice factors were found to not significantly differ between systems $F(2,125)=1.97$ (Programs), 1.97 (Counselling), .52 (Consultation), 1.83 (MSDS), and 1.91 (MSDSi, $p>.05$ ). Table 5 contains the results of post-hoc Tukey HSD analyses conducted on the two significant areas of difference.

Table 5 shows that government-based school psychologists reported significantly higher frequencies of assessment-based tasks and lower job satisfaction than both Catholic and independent-based school psychologists, while no differences were found between the latter two systems.

A one-way ANOVA involving demographic variables indicated that the number of students per psychologist differed significantly across systems, $F(2,125)=18.94$, $p<.001, \eta^{2}=.23$, particularly between Government $(M=1885.86, S D=1047)$ 
TABLE 4

Psychologists' Work Practice Variable Scores By System

\begin{tabular}{lrrrrrrrr}
\hline & \multicolumn{2}{c}{$\begin{array}{c}\text { Government } \\
(N=86)\end{array}$} & & \multicolumn{2}{c}{$\begin{array}{c}\text { Catholic } \\
(N=22)\end{array}$} & & \multicolumn{2}{c}{$\begin{array}{c}\text { Independent } \\
(N=20)\end{array}$} \\
\cline { 2 - 3 } Scale & $M$ & $S D$ & & $M$ & $S D$ & & $M$ & $S D$ \\
\hline Role Assessment & 13.35 & 2.45 & & 11.27 & 2.27 & & 10.50 & 2.76 \\
Role Programs & 5.05 & 0.16 & & 5.23 & 0.33 & 5.80 & 0.34 \\
Role Counselling & 11.14 & 2.18 & & 10.73 & 3.53 & & 12.25 & 1.80 \\
Role Consultation & 20.66 & 0.34 & & 19.91 & 0.68 & & 20.70 & 0.71 \\
MSDS & 15.04 & 0.39 & & 14.23 & 0.77 & & 16.35 & 0.81 \\
MSDSi & 48.10 & 0.92 & 44.27 & 1.80 & & 46.34 & 1.89 \\
Job Satisfaction & 39.86 & 1.17 & & 50.19 & 2.32 & & 51.42 & 2.43 \\
\hline
\end{tabular}

TABLE 5

Mean Differences Between Groups on Assessment and Job Satisfaction Scales

\begin{tabular}{|c|c|c|c|c|c|}
\hline Factor & $\begin{array}{l}\text { System } \\
\text { (I) }\end{array}$ & $\begin{array}{l}\text { System } \\
\text { (J) }\end{array}$ & $\begin{array}{c}\text { Mean difference } \\
(\mathrm{I}-\mathrm{J})\end{array}$ & $\begin{array}{c}\mathrm{Cl} \\
(95 \%)\end{array}$ & $p$ \\
\hline \multirow[t]{3}{*}{ Assessment } & Government & Catholic & 2.08 & $-0.84-0.19$ & .001 \\
\hline & & Independent & 2.85 & $-0.99-0.32$ & $<.001$ \\
\hline & Catholic & Independent & 0.77 & {$[-0.28-0.56]$} & $>.05$ \\
\hline \multirow{3}{*}{$\begin{array}{l}\text { Job } \\
\text { satisfaction }\end{array}$} & Government & Catholic & -10.33 & $-16.55-4.22$ & $<.001$ \\
\hline & & Independent & -11.56 & $-18.03-5.21$ & $<.001$ \\
\hline & Catholic & Independent & -1.23 & $-6.74-9.20$ & $>.05$ \\
\hline
\end{tabular}

and Independent $(M=847, S D=483.38 ; p<.001,95 \%$ CIs [502.63, 1575.09] $)$ and Government and Catholic $(M=816.36, S D=531.67 ; p<.001,95 \%$ CIs $[553.42,1585.57])$ but not Independent and Catholic $(p>.05$; 95\% CIs-636.72697.99).

Correlations. Two-tailed Pearson product-moment correlations were conducted between the items describedabove and several demographic factors.

Table 6 shows that few relationships were established between training/experience and work practice factors. In contrast, the Student-psychologist ratio was found to produce a medium, positive association with Assessment and small and medium, negative associations with Counselling and Job satisfaction. In addition, MSDS scores were found to be positively correlated with all of the activity scales, the strongest being a large correlation with Consultation. While Program also produced a small, positive correlation with Job satisfaction, Assessment showed the opposite relationship. Finally, MSDS scores produced a large, positive correlation with MSDSi scores, and a small, positive correlation with Job satisfaction. The categorisation of effect sizes are as described by Field (2009).

\section{Discussion}

This study centred on the degree to which psychologists, teachers and parents shared perceptions on the role of school psychologists, and investigated the relationships between psychologists' personal/work-based factors, the number of and frequency 
TABLE 6

Pearson Correlations Between Personal/Work-Based Factors and Work Practices

\begin{tabular}{|c|c|c|c|c|c|c|c|c|c|c|c|}
\hline Measure & 1 & 2 & 3 & 4 & 5 & 6 & 7 & 8 & 9 & 10 & 11 \\
\hline 1. Age & - & .03 & $.73^{\star \star \star}$ & -.09 & .10 & .15 & .05 & -.04 & .07 & -.08 & $.26^{\star \star}$ \\
\hline 2. CPD hours & & - & .05 & .08 & .16 & $.20^{*}$ & .03 & .14 & .24 *夫 & .04 & .07 \\
\hline 3. Years of experience & & & - & .03 & .13 & .11 & .11 & .05 & .16 & .01 & $.27^{\star \star \star}$ \\
\hline $\begin{array}{l}\text { 4. Student-psychologist } \\
\text { ratio }\end{array}$ & & & & - & -.07 & .06 & $-.35^{\star \star \star}$ & -.15 & .14 & $.35^{\star \star \star}$ & $-.25^{\star \star}$ \\
\hline 5. MSDS total & & & & & - & $.52^{\star \star \star}$ & $.23^{\star \star}$ & $.43^{\star \star \star}$ & $.50^{\star \star \star}$ & $.19^{\star}$ & $.24^{\star}$ \\
\hline 6. MSDSi total & & & & & & - & .16 & .12 & $.39 * \star \star$ & $.18^{\star}$ & -.05 \\
\hline 7. JS total & & & & & & & - & $.24^{\star \star}$ & .09 & $-.28^{\star \star \star}$ & .11 \\
\hline 8. Program total & & & & & & & & - & $.34^{\star \star \star}$ & .06 & $.36^{\star \star \star}$ \\
\hline 9. Consultation total & & & & & & & & & - & $.28^{\star \star \star}$ & $.32^{\star \star \star}$ \\
\hline 10. Assessment total & & & & & & & & & & - & .07 \\
\hline 11. Counselling total & & & & & & & & & & & - \\
\hline
\end{tabular}

Note: $\mathrm{CPD}=$ continuing professional development; ${ }^{* \star *} p<.001,{ }^{* \star} p<.01,{ }^{\star} p<.05, \mathrm{DF}=134$ 
with which activities were undertaken, the importance placed on systemic practices, and levels of job satisfaction.

Perceptions of the Role of School Psychologists. The first hypothesis was supported. Compared to teachers, parents demonstrated that they were less informed regarding the responsibilities of school psychologists. This result was consistent with higher levels of self-reported understanding and rates of contact with school psychologists reported by teachers. Results showed shared perceptions between school psychologists, parents, and teachers; however, a number of misconceptions were identified that related to role boundaries, confidentiality, informed consent, dual relationships, and particularly relationships between teachers and school psychologists. These differences echo differences in perspectives on the ideal role of school psychologists as identified by Thielking and Jimerson (2006), although the measure was modified in order to assess the actual responsibilities of school psychologists rather than ideal responsibilities.

While parents showed an uninformed understanding of the responsibilities of psychologists in a range of areas such as career guidance, they less frequently identified key aspects of the role such as the assessment of students. This suggests that parents are unaware that psychologists primarily undertake the assessment and counselling of students, rather than careers counselling. This is consistent with the findings of Kelly and Grady (2000) and the misunderstandings described by Agresta (2004) and Fletcher et al. (2010). Parents were also somewhat unclear as to the professional relationship between school psychologists and teachers which would reflect their experience; however, results relating to professional interactions involving confidentiality and dual relationships are somewhat concerning.

Teachers also tended to overrate the responsibilities of school psychologists in relation to students and their own involvement in the process of counselling, access to records, and discipline. Given the confidentiality obligations of psychologists (APS, 2000 as cited in Thielking, 2006), teachers' perceptions that psychologists gave them access to counselling records and frequently informed them of students' attitudes towards them was unexpected. In analysing these differences, although the responses of both parents and teachers indicate a lack of accurate information, those of parents relate to fundamental aspects of the role. Together, these findings highlight that key stakeholders in school-based psychological services could be far better informed as to the role of school psychologists. The education of school communities, particularly parents, regarding the role of school psychologists should therefore be a high priority for the profession.

Differences Between Government, Catholic, and Independent School Psychologists. Hypothesis 2 was not supported. Although it was anticipated that, due to larger participant numbers than in previous research and hence greater statistical power, compared to government and independent psychologists, Catholic-based school psychologists would engage in all tasks at a lower frequency, the only significant difference in work practices was that government-based school psychologists reported a higher frequency of assessment-based tasks than both Catholic and independent school psychologists. This finding is consistent with those of Thielking et al. (2006).

Also consistent with the findings of Thielking et al. (2006), government-based school psychologists reported significantly lower job satisfaction compared to those in the other systems. It therefore appears that the difference is not the overall frequency with which tasks are completed, but the frequency with which assessment-based 
tasks are completed. These results are consistent with the dissatisfaction expressed by school psychologists concerning the large proportion of time designated to these tasks and consequent reduced time available for activities (Bradley-Johnson \& Dean, 2000; Bramlett et al., 2002; Curtis et al., 2002; Farrell, Jimerson, Kalambouka, \& Benoit, 2005; Levinson, 1990; Nastasi, 2004; Watkins, Crosby, \& Pearson, 2001). No differences were found in relation to the number of systemic practices completed, or the importance of these practices, between systems, suggesting considerable consistency across systems.

The Influence of Experience, Training, and Work-Based Factors on Work Practices. Hypothesis 3 was not supported. Although the number of professional development hours positively related to the frequency of consultation, at a level consistent with that found by Curtis et al. (2002), no experience or training factors related to program engagement. This was not totally unexpected, as Curtis and colleagues also failed to find an association between similar factors.

In contrast, based on previous research, inconsistencies in associations between engagement in client-centred tasks and experience/training factors were not anticipated. Assessment-based tasks were found to be associated with no experience or training factors. This may be due to the high frequency with which the majority of psychologists engage in assessment-based tasks. The positive association found between counselling activities and age, along with years of experience, were opposite in direction to that expected, based on the client-centred classification, and were in contrast to the non-significant results found by Curtis et al. (2002). Discrepancies in findings may reflect differences in measurement, as Curtis et al. (2002) required participants to indicate the number of students counselled per year, compared with task frequency used in this study.

Furthermore, no relationship was established between training or experience factors and the number of systemic tasks undertaken. This finding is inconsistent with those of Thielking (2006) and calls into question the notion that more experience leads to more involvement in systemic activities. The overall lack of relationships between the number and frequency of engagement in systemic and client-centred tasks and measures of training and experience also provides little evidence for these factors explaining the frequency with which tasks are undertaken. Potential explanations may involve factors that were not assessed, such as the number of supervision hours, which may better illustrate the relationship between training, experience, comfort with, and the use of systemic practices as discussed by Thielking (2006) and Idsoe (2003).

In relation to restrictive work-based factors, as the number of students per school psychologist increased, the more frequently assessments were conducted and the less frequently counselling was undertaken. The relationships between higher numbers of students per psychologist, increased assessment-based tasks and decreased rates of other tasks is consistent with the findings of Curtis et al. (2002), Farrell (2010), Jimerson, Graydon, Curtis, and Saskal (2007), Thielking (2006), and Worrell (2004). These results suggest that restrictive work demographics have a stronger association with systemic and client-centred work practices than factors relating to experience or on-going training.

The Relationships Between Systemic Practices, Perceived Importance, and Job Satisfaction. In testing hypothesis 4 and gaining an update on the work practices of school psychologists, it is evident that the field continues its slow but steady shift towards widespread use of the systemic approach. While the percentage of school 
psychologists who used an equally systemic/client-centered approach was similar to that found by Thielking (2006), many more were found to use a generally systemic approach, with fewer using a generally client-centred approach. The proportion of psychologists found to use systemic approaches is in stark contrast to the findings of Idsoe (2003). Melbourne-based school psychologists therefore appear to have taken on board the recommendations of research indicating the benefits of systemic practices.

Hypothesis 4 was supported. As expected, a large, positive relationship was established between the number of systemic practices and the level of importance placed on those practices overall. This relationship is consistent with the findings of Thielking (2006). Importantly, those who engaged in a greater number of systemic practices were also found to have higher levels of job satisfaction. In addition, the negative relationship established between the frequency of assessment-based tasks and job satisfaction was equal and opposite to those between program engagement, job satisfaction and the number of systemic activities undertaken. Although the relationships were small, it is proposed that levels of engagement in different tasks can influence job satisfaction in opposing ways. This relates to the evidence that demonstrates that school psychologists prefer to conduct fewer assessments and engage in more non-assessment based tasks (e.g., Bramlett et al., 2002; Hatzichristou, 2004; Levinson, 1990; Roberts, 1970; Watkins et al., 2001). The only demographic factor found to be associated with job satisfaction was the student-psychologist ratio. This finding reinforces the suggested impact of excessive student numbers on the wellbeing of psychologists (Curtis et al., 2002).

Limitations. In the present study, a low response rate was recorded for parents. Given previous response rates as low as $17 \%$ in this area of research (e.g., Cuckle \& Bamford, 2000), the low response rate for parents may represent their uncertainty about the role. The sample, while containing similar numbers of parents, teachers, and school psychologists, was unbalanced in the proportion of government, Catholic, and independent school psychologists compared to parents. Given that the roles were found to be relatively consistent across systems it does not appear that this influenced the outcomes of the study.

While the use of psychologists' responses as indicators of the realities of practice is justified, several significant differences were found between the responses of school psychologists and parents and teachers on items relating to parents and teachers respectively. These discrepancies bring into question the possible influence of social desirability on the responses of school psychologists, both on this and other measures. The discrepancies identified, although significant, were by no means large; however, a consistent pattern emerged of differences in the responses of the three groups. Despite this, generalising the findings to other school psychologists in Melbourne, the state of Victoria, nationally and internationally must therefore be undertaken with caution.

In addition, throughout the present research, the results of Thielking and colleagues (2006) have been used as the benchmark for comparison. This was necessary primarily due to adopting the same methodology and the recruitment of similar participant groups. There are a number of measures which have been developed to examine the work of school psychologists that could have been used in this study; however, the availability of a local instrument which had been used with similar participants,and given the changes made since its introduction gave compelling reasons for its use. 
Future Research. The introduction of this article identified that investigating the perspectives of the educational community regarding the role of school psychologists was an important first step. It is therefore suggested that future research be conducted to identify the impact that an increase in knowledge regarding the role of school psychologists has on services. This may be achieved through public promotion of the services provided by these practitioners, their areas of knowledge, and their key responsibilities. It would be predicted that this would result in a closer alignment between the perceptions of parents and teachers and the role reported by school psychologists themselves. In turn, this shared understanding may influence the use and/or the effectiveness of the service.

\section{Conclusion}

From the results obtained, a number of conclusions are evident. First, parents and teachers need to be better informed regarding the role of school psychologists by individual practitioners and the professional bodies that represent them. Second, despite differences in the frequency of assessments and job satisfaction, the role of psychologists across government, Catholic, and independent schools is relatively consistent and there is a mix of client-based and systemic work undertaken. Furthermore, it is not the frequency of task engagement in general that is associated with job satisfaction but the frequency with which particular tasks are carried out. Specifically, more frequent engagement in assessment-based tasks and less frequent engagement in systemic tasks is associated with lower levels of job satisfaction. Third, the tasks school psychologists engage in are more closely associated with student-psychologist ratios than personal factors relating to ongoing training or experience. The authors would like to note that a number of additional factors may influence the tasks carried out by school psychologists. For example, the training of psychologists at the university level and the focus placed on systemic practices within those programs would be expected to play a role in determining a practitioner's approach. In addition, the current climate within which psychologists work and the particular emphasis that is placed on the use of psychometric assessments, not only in determining eligibility for funding but in general practice, and the impact that this has on engagement in non-assessment based tasks should be acknowledged. However, given the current results, school psychologists and their employing bodies might reconsider the priorities given to particular services and how they can be implemented adequately. In order to assist school psychologists to provide more systemic practices and to do so at higher frequencies, more psychologists are required, particularly in the government system. A greater number of psychologists in the school systems would be predicted to facilitate not only the delivery of non-assessment based services but increased job satisfaction, with positive effects on performance, productivity, decreased absenteeism, and turnover (Levinson, 1990). Finally, an increasing number of school psychologists report that they are able to find a balance between client-centered and systemic tasks. With support from research and continued encouragement from professional bodies, perhaps the demonstrated positive relationship between systemic work and job satisfaction can provide the motivation to sustain systemic practices in the activities of psychologists, and encourage psychologists and service providers to maintain broad role descriptions in the context of schools. 


\section{Financial Support}

This research received no specific grant from any funding agency, commercial, or not-for-profit sectors.

\section{Conflict of Interest}

None.

\section{Ethical Standards}

The authors assert that all procedures contributing to this work comply with the ethical standards of the relevant national and institutional committees on human experimentation and with the Helsinki Declaration of 1975, as revised in 2008.

\section{References}

Agresta, J. (2004). Professional role perceptions of school social workers, psychologists, and counselors. Children and Schools, 26, 151-163. doi: $10.1093 / \mathrm{cs} / 26.3 .151$

Anderson, W.T., Hohenshil, T.H., \& Brown, D.T. (1984). Job satisfaction among practicing school psychologists: A national study. School Psychology Review, 14, 225-230. Retrieved from http://www.psycnet. apa.org/psycinfo/1984-29827-001

Annan, J., \& Priestley, A. (2011). A contemporary story of school psychology. School Psychology International, 33(3), 325-344. doi:10.1177/0143034311412845

Armstrong, S., Kelly, P., Phillips, J., Royle, B., White, J., \& Yates, K. (2000). The status of school counselling and guidance in Australia: A summary report. Australian Guidance and Counselling Newsletter, 2, $20-25$.

Australian Psychological Society (APS). (2000). Standards for the delivery of school psychological services. Retrieved May, 2011, from http://www.psychology.org.au/members/ethics/ed_standards.pdf

Australian Psychological Society (APS). (2009). Framework for the effective delivery of school psychological services. Retrieved May, 2011 from http://www.psychology.org.au/Assets/Files/Framework-schoolpsychological-services.pdf

Australian Psychological Society. (2011). Guidelines on continuing professional development (CPD) requirements. Melbourne, Australia: The Australian Psychological Society Limited.

Bradley-Johnson, S., \& Dean, V.J. (2000). Role change for school psychology: The challenge continues in the new millennium. Psychology in the Schools, 37(1), 1-5. doi:10.1002/(SICI)15206807(200001)37:1<1::AID-PITS1>3.0.CO;2-Q

Bramlett, R.K., Murphy, J.J., Johnson, J., Wallingsford, L., \& Hall, J.D. (2002). Contemporary practices in school psychology: A national survey of roles and referral problems. Psychology in the Schools, 39(3), 327-335. doi:10.1002/pits.10022

Brown, J.E. (1987). A systemic view of psychological consultation in schools. Canadian Journal of Counselling, 21, 2-3. Retrieved from http://www.cjc-rcc.ucalgary.ca/cjc/index.php/rcc/article/ viewFile/1343/1222

Cuckle, P., \& Bamford, J. (2000). Parents' evaluation of an educational psychology service. Educational Psychology in Practice, 16(3), 361-371. doi:10.1080/02667360020006426

Cummings, J.A., Harrison, P.L., Dawson, M.M., Short, R.J., Gorin, S., \& Palomares, R.S. (2004). The 2002 conference on the future of school psychology: Implications for consultation, intervention, and prevention services. Journal of Educational and Psychological Consultation, 15(3\&4), 239-256. doi:10.1080/10474412.2004.9669516

Curtis, M.J., Hunley, S.A., \& Grier, J.E.C. (2002). Relationships among the professional practices and demographic characteristics of school psychologists. School Psychology Review, 31(1), 30-42. Retrieved from http://www.psycnet.apa.org/psycinfo/2002-02916-003 
Department of Education. (1998). Framework for student support services in Victorian Government schools. Retrieved from http://www.cyf.vic.gov.au/_data/assets/pdf_file/0017/16730/frame_ student_support.pdf

Farrell, P. (2010). School psychology: learning lessons from history and moving forward. School Psychology International, 31(6), 581-598. doi:10.1177/0143034310386533

Farrell, P., Jimerson, S.R., Kalambouka, A., \& Benoit, J. (2005). Teachers' perceptions of school psychologists in different countries. School Psychology International, 26, 525-544. doi:10.1177/ 0143034305060787

Field, A. (2009). Discovering statistics using SPSS (3rd ed.). London: Sage Publications.

Fletcher, J., Bloor, K., Crossman, C., Thornton, J., Briggs, E., Hawkins, T., Sammut, S., \& Cardwell, K. (2010). Profiling the college of educational and developmental psychologists: An examination of demographics, professional practice, attitudes and professional developmental preferences. The Australian Educational and Developmental Psychologist, 27(1), 1-19. doi:10.1375/aedp.27.1.1

Gilman, R., \& Gabriel, S. (2004). Perceptions of school psychological services by education professionals: Results from a multi-state survey pilot study. School Psychology Review, 33(2), 271-286.

Gutkin, T.B., \& Conoley, J.C. (1990). Reconceptualizing school psychology from a service delivery perspective: implications for practice, training, and research. Journal of School Psychology, 28, $203-223$. doi:10.1016/0022-4405(90)90012-V

Hair, J.F., Anderson, R.E., Tatham, R.L., \& Black, W.C. (1998). Multivariate data analysis (5th ed.). Upper Saddle River, NJ: Prentice Hall.

Hart, S. (2007). The handbook of international school psychology: A review with implications for the profession's future. School Psychology International, 28, 523-540. doi:10.1177/0143034307085656

Hatzichristou, C. (2004). Alternative school psychological services: Development of a model linking theory, research and service delivery. In N.M. Lambert, I. Hylander \& J. Sandoval (Eds.), Consultee-Centered Consultation: Improving the quality of professional services in schools and community organizations (pp. 115-132). Mahwah, NJ: Lawrence Erlbaum.

Idsoe, T. (2003). Work behavior in the school psychology service: Conceptual framework and construct validity approached by two different methodologies. Journal of School Psychology, 41, 313-335. doi:10.1016/S0022-4405\%2803\%2900084-0

Jimerson, S., Graydon, K., Curtis, M., \& Saskal, R. (2007). International School Psychology Survey: Insights from around the world. In S. Jimerson, T. Oakland, \& P. Farrell (Eds.), The handbook of international school psychology. Thousand Oaks, CA: Sage Publications.

Kahl, L.J., \& Fine, M.J. (1978). Teachers' perceptions of the school psychologist as a function of teaching experience, amount of contact, and socioeconomic status of the school. Psychology in the Schools, 15(4), 577-582. doi:10.1002/1520-6807(197810) 15:4<577::AIDPITS2310150423>3.0.CO;2-9

Kelly, D., \& Grady, C. (2000). Educational psychology services (England): Current role, good practice, and future directions - The research report (DfEE 0133/2000). Nottingham, England: Department for Education and Employment. Retrieved from http://www.dera.ioe.ac.uk/12356/

Leadbetter, J. (2005). Activity theory as a conceptual framework and analytical tool within the practice of educational psychology. Educational and Child Psychology, 22, 18-28.

Levinson, E.M. (1989). Job satisfaction among school psychologists: A replication study. Psychological Reports, 65, 579-584. doi:10.2466/pr0.1989.65.2.579

Levinson, E.M. (1990). Actual/desired role functioning, perceived control over role functioning, and job satisfaction among school psychologists. Psychology in the Schools, 27, 64-74. doi:10.1002/15206807(199001)27:1<64::AID-PITS2310270110>3.0.CO;2-6.

Meyers, J., Meyers, A.B., \& Grogg, K. (2004). Prevention through consultation: A model to guide future development in the field of school psychology. Journal of Educational and Psychological Consultation, 15(3\&4), 257-276. doi:10.1080/10474412.2004.9669517

Meyers, J., Roach, A.T., \& Meyers, B. (2009). Engaging in the debate: A critique of Blueprint III. Journal of Educational and Psychological Consultation, 19, 197-223. doi:10.1080/10474410903117239

Nastasi, B.K. (2004). Meeting the challenges of the future: integrating public health and public education for mental health promotion. Journal of Educational and Psychological Consultation, 15(3\&4), 295-312. 
National Association of School Psychologists. (2010). Model for comprehensive and integrated school psychological services. School Psychology Review, 39(2), 320-333.

Perfect, M.M., \& Morris, R.J. (2011). Delivering school-based mental health services by school psychologists: Education, training, and ethical issues. Psychology in the Schools, 48(10), 1049-1063. doi:10.1002/pits.20612

Psychology Board of Australia. (2012). Continuing Professional Development Registration Standard. Retrieved May 2011 from http://www.psychologyboard.gov.au/documents/default.aspx?record= WD10\%2f248\&dbid=AP\&chksum $=4 \mathrm{kAyox} 8 \mathrm{nd} \% 2 \mathrm{fkIIJY} 2 \mathrm{pmMqqg} \% 3 \mathrm{~d} \% 3 \mathrm{~d}$

Reschly, D.J., \& Yesseldyke, J.E. (2002). Paradigm shift: The past is not the future. In A. Thomas \& J. Grimes (Eds.), Best practices in school psychology (4th ed., pp. 3-20). Bethesda, MD: National Association of School Psychologists.

Roberts, R.D. (1970). Perceptions of actual and desired role functions of school psychologists by psychologists and teachers. Psychology in the schools, 7(2), 175-178. doi:10.1002/15206807(197004)7:2<175::AIDPITS2310070213>3.0.CO;2-2

Robinson, J.P., Shaver, P.R., \& Wrightsman, L.S. (Eds.). (1991). Measures of personality and social psychology attitudes. San Diego: Academic Press.

Sheridan, S.M., \& Gutkin, T.B. (2000). The ecology of school psychology: Examining and changing our paradigm for the 21st century. School Psychology Review, 29(4), 485-502.

Spector, P.E. (1997). Job satisfaction: application, assessment, causes and consequences.Thousand Oaks, CA: Sage.

Stobie, I. (2002). Processes of 'change' and 'continuity' in educational psychology — Part II. Educational Psychology in Practice, 18(3), 213-237. doi:10.1080/0266736022000010258

Stobie, I., Gemmell, M., Moran, E., \& Randall, L. (2002). Challenges for educational psychologists and their services: a qualitative analysis. School Psychology International, 23, 243-265. doi:10.1177/0143034302023003232

Tabachnick, B.G., \& Fidell, L.S. (2007). Using multivariate statistics (5th ed.). Boston: Pearson/Allyn \& Bacon.

Thielking, M. (2006).An investigation of attitudes towards the practice of school-based psychological services. Unpublished manuscript, School of Life and Social Sciences, Swinburne University of Technology, Melbourne, Australia.

Thielking, M., \& Jimerson, S.R. (2006). Perspectives regarding the role of school psychologists: perceptions of teachers, principals, and school psychologists in Victoria, Australia. Australian Journal of Guidance \& Counselling, 16(2), 211-223.

Thielking, M., Moore, S., \& Jimerson, S.R. (2006). Supervision and satisfaction among school psychologists: An empirical study of professionals in Victoria, Australia. School Psychology International, 27, 405-414. doi:10.1177/0143034306070426

Watkins, M.W., Crosby, E.G., \& Pearson, J.L. (2001). Role of the school psychologist: Perceptions of school staff. School Psychology International, 22(1), 64-73.

Worrell, T. (2004). School psychologists' job satisfaction: Ten years later. Unpublished manuscript, School of Education, Virginia Polytchnic Institute and State University, VI.

Young, A., \& Cavanagh, R. (2009, November-December). A Rasch modelling approach to measuring school need for psychological services. Paper presented at the Annual Conference of the Australian Association for Research in Education, Canberra, Australia. Retrieved from http://www.aare.edu. au/09pap/you091368.pdf 